\title{
Redressing the interactions between stem cells and immune system in tissue regeneration
}

\author{
Jiankai Fang ${ }^{1+} \mathbb{D}$, Chao Feng $^{1,2+}$, Wangwang Chen ${ }^{3}$, Pengbo Hou ${ }^{1,2}$, Zhanhong Liu ${ }^{1,2}$, Muqiu Zuo ${ }^{1}$,

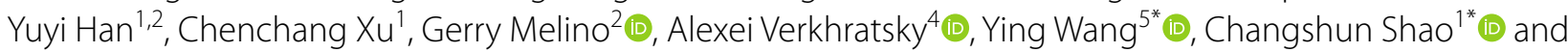 \\ Yufang Shi ${ }^{1,5^{*}}$
}

\begin{abstract}
Skeletal muscle has an extraordinary regenerative capacity reflecting the rapid activation and effective differentiation of muscle stem cells (MuSCs). In the course of muscle regeneration, MuSCs are reprogrammed by immune cells. In turn, MuSCs confer immune cells anti-inflammatory properties to resolve inflammation and facilitate tissue repair. Indeed, MuSCs can exert therapeutic effects on various degenerative and inflammatory disorders based on their immunoregulatory ability, including effects primed by interferon- $\gamma$ (IFN- $\gamma$ ) and tumor necrosis factor- $a$ (TNF- $a)$. At the molecular level, the tryptophan metabolites, kynurenine or kynurenic acid, produced by indoleamine 2,3-dioxygenase (IDO), augment the expression of TNF-stimulated gene 6 (TSG6) through the activation of the aryl hydrocarbon receptor (AHR). In addition, insulin growth factor 2 (IGF2) produced by MuSCs can endow maturing macrophages oxidative phosphorylation (OXPHOS)-dependent anti-inflammatory functions. Herein, we summarize the current understanding of the immunomodulatory characteristics of MuSCs and the issues related to their potential applications in pathological conditions, including COVID-19.
\end{abstract}

Keywords: MuSCs, Immune cells, Immunomodulation, Muscle repair, Tissue regeneration

\section{Introduction}

For centuries, biologists have been puzzled with the near perfect ability to regenerate severed body parts in certain animals. Planarians, for example, even after being sliced into 100 segments, demonstrate remarkable regeneration when each of the pieces develops into individual worm with normal adult structure. A salamander completely regrows amputated limbs with normal tissue structures

\footnotetext{
*Correspondence: yingwang@sibs.ac.cn; shaoc@suda.edu.cn; yfshi@suda. edu.cn

${ }^{\dagger}$ Jiankai Fang and Chao Feng have contributed equally to this article ${ }^{1}$ The Third Affiliated Hospital of Soochow University, Institutes for Translational Medicine, State Key Laboratory of Radiation Medicine and Protection, Medical College of Soochow University, 199 Renai Road, Suzhou 215123, Jiangsu, People's Republic of China

${ }^{5}$ Shanghai Institute of Nutrition and Health, Shanghai Institutes

for Biological Sciences, Chinese Academy of Sciences, 320 Yueyang Road, Shanghai 200031, People's Republic of China

Full list of author information is available at the end of the article
}

and functions [1-4]. Mechanisms of accurate coordination of diverse and complex biological processes, including, but not limited to, angiogenesis, skeletal reconstruction, muscle layout, and nerve innervation during tissue regeneration remain largely elusive and merit further investigations.

Tissue regeneration is a highly orchestrated process that is often accompanied by inflammation. The infiltration of immune cells into the injured site is one of the earliest detectable responses to tissue damage. Various aspects of inflammation, such as the duration, severity, and the types of immune response, determine the outcomes of tissue regeneration [5-7]. Persistent deregulated inflammation at the injury site derails the regeneration process and eventually leads to the formation of tissue fibrosis and scars. Successful tissue regeneration requires an orderly coordination of activation and waning of different types of inflammatory responses

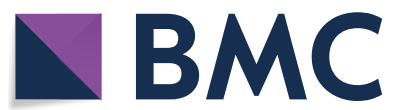

(c) The Author(s) 2021. Open Access This article is licensed under a Creative Commons Attribution 4.0 International License, which permits use, sharing, adaptation, distribution and reproduction in any medium or format, as long as you give appropriate credit to the original author(s) and the source, provide a link to the Creative Commons licence, and indicate if changes were made. The images or other third party material in this article are included in the article's Creative Commons licence, unless indicated otherwise in a credit line to the material. If material is not included in the article's Creative Commons licence and your intended use is not permitted by statutory regulation or exceeds the permitted use, you will need to obtain permission directly from the copyright holder. To view a copy of this licence, visit http://creativecommons.org/licenses/by/4.0/. The Creative Commons Public Domain Dedication waiver (http://creativeco mmons.org/publicdomain/zero/1.0/) applies to the data made available in this article, unless otherwise stated in a credit line to the data. 
mediated by distinct immune cell populations [8]. The immune aspect of tissue repair was not appreciated until Elie Metchnikoff discovered the role of macrophages in starfish wound healing in 1882 when being in Messina [9]. Numerous breakthroughs have been made over the recent two decades and laid a solid foundation for understanding the pathogenesis of traumatic diseases and for developing more efficient therapies, including the effects on redox, epigenetics, transcriptional, degradative, apoptotic and autophagic mechanisms [10-26].

Skeletal muscle is a major immunomodulatory organ [27]. In addition to myogenic cells, a large number of immune cells reside in healthy skeletal muscle tissue. There are 500 to 2000 leukocytes per $\mathrm{mm}^{3}$ of adult rodent limb muscles. Skeletal muscle is the largest tissue, accounting for approximately $35 \%$ of the total body mass of a human and containing about $10^{9}$ leukocytes per liter of muscle tissue. Total number of leukocytes in a typical adult is $4 \times 10^{11}$, while there are $4 \times 10^{10}$ leukocytes in the entire muscle [28]. T cells, neutrophils and eosinophils are less abundant in healthy skeletal muscle, whereas monocytes and macrophages account for the majority of resident immune cell populations. They are scattered in the interstices of muscle connective tissue and around blood vessels $[29,30]$. The muscle immune system represents an excellent platform for investigating the interactions between stem cells and immune cells in tissue regeneration.

Muscle damage caused by trauma, burns, freezing, toxins, over-exercise or certain diseases often disrupts the original tissue structure. Muscle stem cells (MuSCs; satellite cells), laying along the fully differentiated myofibers, exit quiescence state and execute the stereotypical myogenesis program in response to muscle damage. The process of recruiting MuSCs into the reparative action can be broadly divided into (i) an early stage of MuSC activation and proliferation, and (ii) a later stage of terminal differentiation and growth $[28,31]$. This regenerative process is accompanied by two distinct immunological phases: (i) the pro-inflammatory phase, where leukocytes migrate towards the injured site to exert pro-inflammatory functions and govern MuSC activation and proliferation, and (ii) the anti-inflammatory or restorative phase, which is characterized by myogenic lineage differentiation, growth of new myofibers, angiogenesis, and extracellular matrix (ECM) deposition and remodeling [32, 33] (Fig. 1).

\section{Regulation of myogenesis by pro-inflammatory responses}

Immune cells are temporally and spatially orchestrated in response to muscle injury. Complement system, the first sensor of muscle damage, is rapidly activated in the injured area [34]. Subsequently, a cellular response occurs, during which activated resident mast cells swiftly degranulate and release pro-inflammatory cytokines to recruit other immune cells to muscle lesions [35, 36]. Within hours, neutrophils, among the first wave of peripheral immune cells, extravasate from circulation and enter the injured area, clean necrotic debris, and mount a pro-inflammatory response [37]. Waves of pro-inflammatory cytokines, such as IFN- $\gamma$, IL- $1 \beta$, TNF- $\alpha$, IL- 1 and IL-8, are secreted from neutrophils and induce the infiltration of circulating monocytes to establish the early inflammatory microenvironment and the subsequent degradation of injured tissues [38, 39]. Macrophages, the professional phagocytes of the immune system, scavenge cellular debris to prevent the persistence of potentially toxic or immunogenic materials in the muscle environment $[8,40]$. The fibro/adipocyte progenitors (FAPs), activated by IL-4-derived from eosinophils, are the nonprofessional phagocytes that mediate rapid debris clearance [41]. Surprisingly, compared to macrophages, FAPs were four-fold more efficient at phagocytizing necrotic thymocytes obtained through iterative cycles of freeze/ thaw in liquid nitrogen in vitro [41].

The muscle environment orchestrated by macrophages and enriched with pro-inflammatory cytokines is essential for the initial stages of myogenesis. The destruction of CCL2/CCR2 axis, the main attractant of circulating monocytes into a damaged site, through genetic ablation of $\mathrm{Ccl} 2$ or its receptor $\mathrm{Ccr} 2$ reduced infiltrating macrophage numbers in injured muscle, and was accompanied by slowed growth of nascent muscle fibers [4245]. Other parallel investigations employing myeloid depletion models (clodronate, CD11b-DTR mouse) also highlighted the absolute requirement of macrophages in governing muscle inflammation and triggering myogenic program following injury [46]. In addition, complement protein $\mathrm{C} 3 \mathrm{a}$ has been implicated in promoting the trafficking of macrophages in damaged muscles to facilitate tissue regeneration [47].

However, infiltrating macrophages exhibit distinct phenotypic characteristics and functions in different phases of skeletal muscle regeneration [32, 48]. The dichotomy between M1 (classically activated) and M2 (alternatively activated) macrophages represents distinct polarized phenotypes, signifying the transition from a pro-inflammatory to an anti-inflammatory/ restorative profile. Nevertheless, this M1-M2 terminology does not reflect sequential and pleiotropic characteristics of infiltrating macrophages [49]. Ly6C ${ }^{+}$or $\mathrm{MHC}^{-}$macrophages that first arrive at the injury site and the $\mathrm{Ly}_{6} \mathrm{C}^{-}$or $\mathrm{MHC}^{+}$macrophages present in the later phases of skeletal muscle regeneration may represent M1-biased and M2-biased populations, respectively [50, 


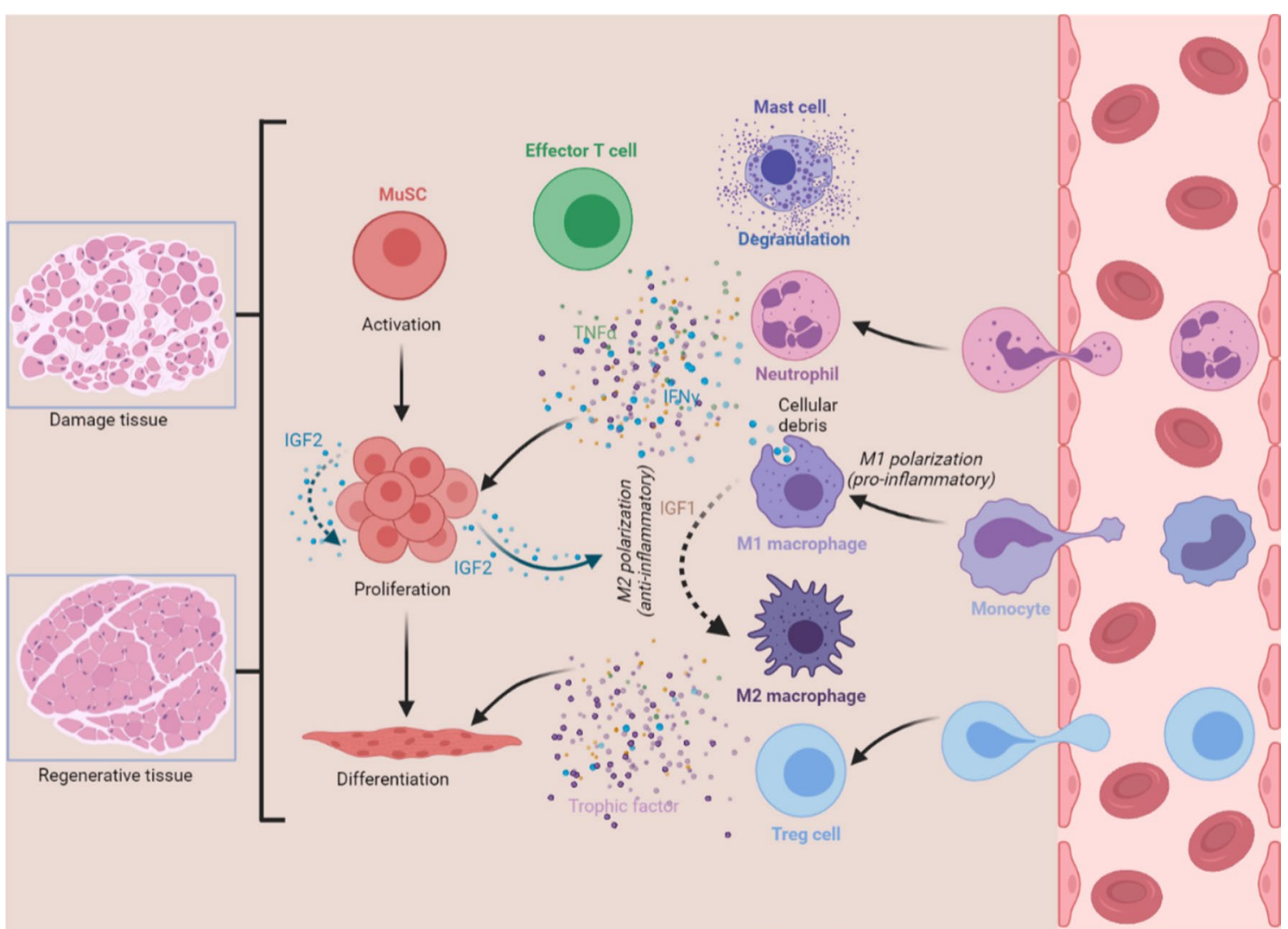

Fig. 1 The reciprocal interaction between MuSCs and immune cells during muscle regeneration. Trauma to muscle evokes dramatic immune challenge. Within hours, damaged muscle tissue experiences mast cell degranulation, invasion by neutrophils, infiltration by M1 macrophages, and trafficking of effector T cells. These immune cells condition the inflammatory environment that is enriched with proinflammatory cytokines, including IFN- $\gamma$ and TNF-a, and direct rapid expansion of the MuSC population. The shift of macrophage phenotype functionally couples with the transition of stages of myogenesis. IGF1 modulates autocrine polarization of pro-inflammatory macrophages towards a M2 phenotype. Treg cells also promote the transition of macrophage phenotype through paracrine action of IL-10. Furthermore, MuSCs could orchestrate inflammatory microenvironments through directing the switch towards anti-inflammatory macrophages via the action of IGF2. The resolution of inflammation through multiple mechanisms drives the later stages of MuSC differentiation. Thus, the bidirectional interaction between MuSCs and immune cells determines the course and outcome of muscle regeneration

51]. M1 macrophages contribute to a spectrum of proinflammatory cytokines, including, but not limited to, IFN- $\gamma$, TNF- $\alpha$, IL- $1 \beta$ and IL- 6 , conditioning the immune microenvironment to promote the rapid proliferation of MuSCs and simultaneously restrain the early differentiation steps of MuSCs [48, 52-56]. Moreover, these pro-inflammatory macrophages, through their expression of TNF- $\alpha$, directly induce apoptosis of FAPs, thus regulating their number and ultimately preventing pathological muscle fibrosis [57]. Macrophage-derived niche signals are vital for MuSC proliferation. The 'dwelling' macrophages, a specific subset of macrophages within the injury area, secrete nicotinamide phosphoribosyltransferase (NAMPT), which, as mitogenic stimuli, activates MuSCs through CCR5 [58]. However, the variety and concentration of inflammatory factors produced by myeloid cells cannot meet the needs of extensive expansion of MuSCs. Hence, T cells play an important role in conditioning the endogenous inflammatory microenvironment and maintaining exponential growth of MuSCs. Specifically, the cocktail of four cytokines (IL$1 \alpha$, IL-13, IFN- $\gamma$ and TNF- $\alpha$ ) secreted from activated T cells assures MuSC expansion in $\mathrm{Rag1}^{-/-}$mice that lack $\mathrm{T}$ cells but have intact macrophages, and promoted the proliferation of undifferentiated MuSCs through 20 passages in vitro [59]. The addition of these four cytokines in culture medium, mimicking the endogenous inflammatory microenvironment, presents a promising method to efficiently expand MuSCs without loss of self-renewing potency, and breaks the bottleneck that had limited longterm serial expansion of functional MuSCs to meet the demands for clinical therapeutic applications [60]. 


\section{Regulation of myogenesis by anti-inflammatory responses}

The resolution of inflammation, associated with the transition from the pro-inflammatory to the anti-inflammatory phase, is functionally coupled to the transition of regeneration states from the proliferative stage to the differentiation and growth stage of myogenesis and is required for tissue recovery [28]. M2 macrophages are crucial in avoiding detrimental inflammation and returning to tissue homeostasis. They contribute to myogenesis, angiogenesis, and ECM remodeling through reciprocal interactions with surrounding cells, including MuSCs, endothelial cells and FAPs [48, 50, 57, 61, 62]. Advances have recently been made in the understanding of the mechanisms governing the spatiotemporal phenotype shift of macrophages. Various metabolic programs can control macrophage inflammatory status [63, 64]. Mass spectrometry-based lipidomics coupled with transcriptomics identified a temporal shift of lipid metabolism, from pro-inflammatory lipid mediators (e.g., leukotrienes, prostaglandins) to specialized pro-resolving lipid mediators (e.g., resolvins and lipoxins), in the transition from $\mathrm{Ly}_{6 \mathrm{C}^{+}}$macrophages to Ly6C ${ }^{-}$macrophages [65]. In particular, activation of the metabolic regulator AMPactivated protein kinase $\alpha 1$ (AMPK $\alpha 1)$ is required for the shift of macrophage polarization. Myeloid-specific deletion of AMPK $\alpha 1$ using lysozyme M-Cre (LysM-Cre) mouse strain resulted in exacerbated muscle damage and delayed repair/regeneration while infiltrating macrophages during the first phase failed to skew from a proinflammatory to an anti-inflammatory phenotype at the time of resolution of inflammation [66]. Insulin growth factor 1 (IGF1) possesses pleiotropic biological functions in M1 macrophages. On the one hand, it exerts paracrine action on activated MuSCs to facilitate their proliferation. On the other hand, myeloid cell-derived IGF1 also influences the outcomes of muscle regeneration through an autocrine effect, which regulates the transition of infiltrating macrophages from a M1 to a M2 phenotype [67, 68]. Prostaglandin E2 (PGE2), another important immunosuppressive factor, can inhibit the proliferation of $\mathrm{T}$ cells, reduce the toxic effects of NK cells, and shape the functions and phenotypes of macrophages [69-71]. In addition, PGE2 also acts as a strong mitogen for MuSCs, through binding to the EP4 receptor on their own surface, triggering the intracellular cAMP/phosphor-CREB pathway and activating the proliferation-inducing transcription factor Nurr1, ultimately robustly augmenting MuSC expansion [72]. Regulatory T (Treg) cells are also crucial for returning to the homeostasis of injury muscles $[73,74]$. Depletion of Treg cells slowed regeneration, prolonged inflammation and perturbed the expression of myogenic transcription factors while the accrual and the polarization towards the M2 phenotype of muscle macrophages in vivo could not be completed $[51,75,76]$.

\section{Mechanisms of immunomodulation by MuSCs}

Muscle regeneration involves highly coordinated cellular responses between different varieties of immune cells and MuSCs. Disturbance of the coordination between the different types of cells will lead to delay or even failure of muscle repair. The synchronized functional changes of trafficking macrophages during skeletal muscle regeneration directly determine MuSC fate and myogenesis progress. Inflammatory factors released from activated T cells in high concentrations promote MuSCs to enter the cell cycle and rapidly proliferate, thus ensuring plenty of stem cell reserves for muscle regeneration. Mounting evidence has confirmed the critical roles of immune cells in directing the fate of MuSCs. However, it is unclear whether there is a bidirectional interaction between immune cells and MuSCs so that MuSCs can in turn regulate the functions of immune cells.

Skeletal muscle is not only an important endocrine tissue, but also one of the main immunomodulatory organs [27]. Myocytes, non-professional antigen-presenting cells, actively participate in the functional regulation of immune cells under physiological and pathological conditions. Myocytes participate in the innate immune response and affect adaptive immunity through secreting myokines [77]. Muscle trauma is accompanied by prominent myocyte necroptosis, in which tenascin-C released by necroptotic myofibers promotes MuSC proliferation to facilitate muscle regeneration [78]. Beside myocytes, do MuSCs, the main myogenic cells in the damaged tissue microenvironment endowed mitogenic functions of necroptosis and pro-inflammatory cytokines, also possess immunomodulatory properties?

We have recently addressed this question experimentally using an inflammatory bowel disease (IBD) model in vivo (Fig. 2). We identified a novel anti-inflammatory function of MuSCs that is based on their production of IGF2. By endowing maturing macrophages an oxidative phosphorylation (OXPHOS)-dependent anti-inflammatory property, the IGF2-producing MuSCs can thus orchestrate an anti-inflammatory microenvironment that favors tissue repair and regeneration in colon tissues [79]. TNF-stimulated gene 6 (TSG6), an important immunoregulatory factor, can suppress inflammation by inducing pro-inflammatory macrophages to adopt an anti-inflammatory phenotype in LPS-induced acute lung injury and dextran sulfate sodium (DSS)-induced colitis model $[80,81]$. MuSCs stimulated by inflammatory factors IFN- $\gamma$ and TNF- $\alpha$ exhibit an anti-inflammatory function that depends on the indoleamine 2,3-dioxygenase (IDO)-TSG6 axis in IBD mice. Mechanistically, the 


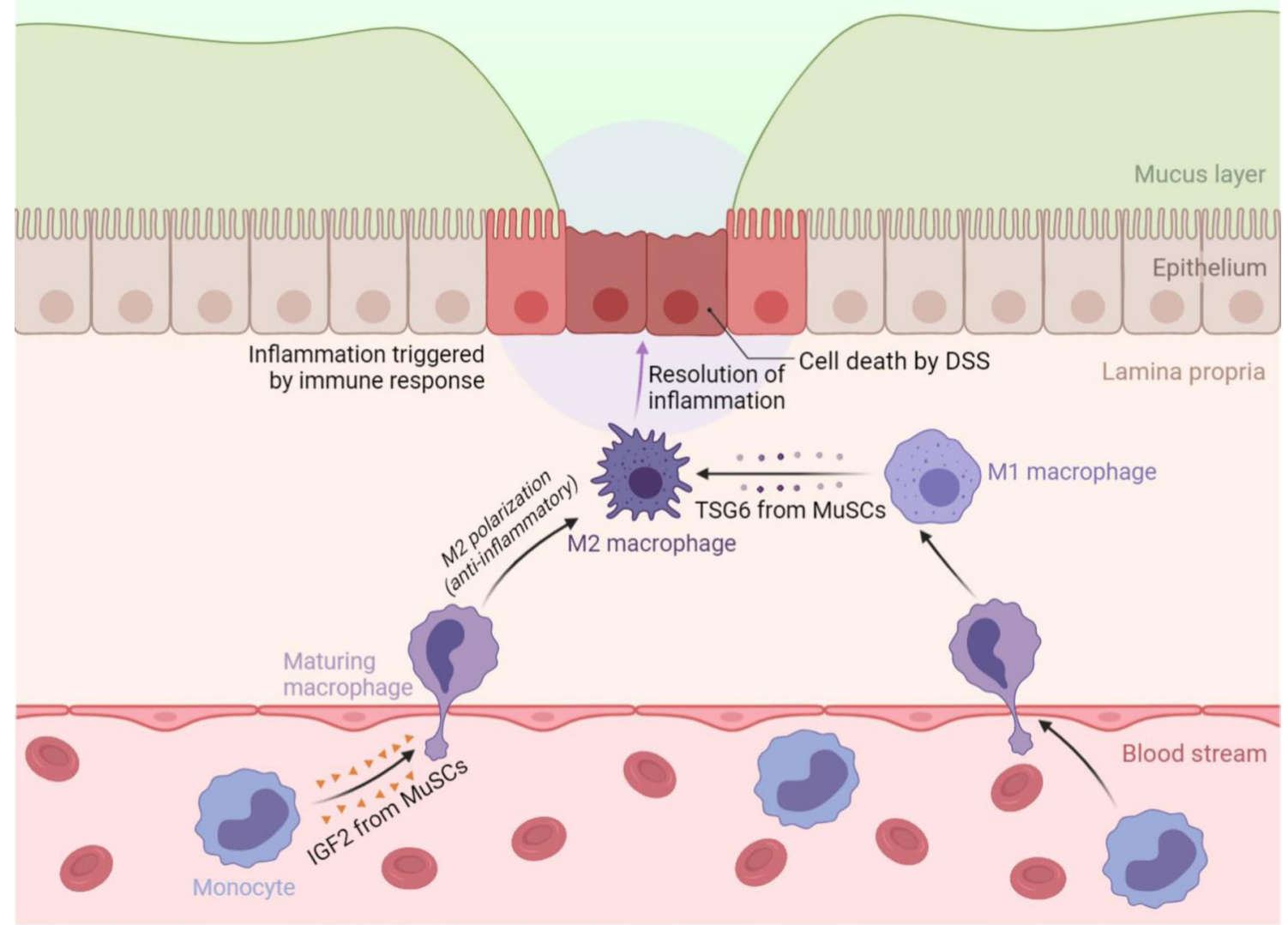

Fig. 2 The immunomodulatory properties of MuSCs during colon inflammation. The resolution of inflammation allows tissue to return to homeostasis. The immunomodulatory properties of MuSCs are required from this process. On the one hand, MuSCs can act on maturing macrophages and confer them with anti-inflammatory properties via IGF2 secretion, thus ameliorating DSS-induced colitis and facilitating tissue repair. On the other hand, inflammatory cytokines-licensed MuSCs, particularly with IFN- $\gamma$ and TNF- $a$, can also alleviate DSS-induced colitis through IDO metabolites-mediated TSG6 production, which mediates the switch of macrophages from a M1 to a M2 phenotype

IDO metabolites kynurenine (KYN) or kynurenic acid (KYNA) promote TSG6 expression through activating aryl hydrocarbon receptor (AHR) signaling [82]. Thus, MuSCs do not only respond to inflammatory cues in damage microenvironment but also act on immune cells to shape immune microenvironment to facilitate tissue repair. The new discovery of MuSCs-based immunomodulatory ability expands the potential applications of stem cell therapies in pathological conditions beyond musclerelated diseases.

\section{New modes of MuSC-based therapy}

There has been a long-standing debate about stem cellbased regeneration and repair mechanism, is it based on cell replacement or cell empowerment. Indeed, only few transplanted stem cells are capable of differentiating into daughter cells at the damaged site or even persisting for a sufficiently long period in vivo [83]. In addition, the results from animal experiments of xenotransplantation and preclinical studies of allogeneic stem cell transplantation have clearly demonstrated therapeutic potentials of stem cell 'decellularization', thus strongly supporting cell empowerment as the paradigm of stem cell therapy. Stem cells 'licensed' by inflammatory factors can dictate the phenotypes and functional metamorphoses of immune cells by producing immunoregulatory factors, and guide the outcomes of inflammation in various diseases. Mesenchymal stem cells (MSCs) can unleash powerful therapeutic effects under different kinds of inflammatory conditions via cell empowerment $[84,85]$. In our study, we found that the MuSC secretome possessed a therapeutic efficacy equivalent to that of MSCs in IBD mice, thus indicating that MuSCs can promote tissue repair indirectly through cell empowerment [79]. It was also demonstrated that MuSCs' exosomes could prevent excessive ECM deposition and facilitate muscle regeneration via regulating collagen expression in fibrogenic cells [86]. Further validation of cell empowerment 
or promotion of tissue homeostasis by stem cells in physiological and pathological conditions will advance our understanding of MuSC biology and expand the application scope of MuSCs.

IGF2, a strong mitogen for MuSCs [87], is a vital immunomodulatory mediator that confers maturing macrophages anti-inflammatory properties [79, 88, 89]. The actions of IGF2 are coupled temporally and spatially to the myogenesis program between MuSC proliferation and immunomodulation. During the early stage of muscle regeneration, MuSCs produce IGF2 to promote self-proliferation and expansion. However, along with the mounting number of MuSC populations, the local concentration of IGF2 in tissue microenvironments becomes sufficiently high to determine the inflammatory phenotypes of infiltrating immune cells. In this scenario, the tissue microenvironment completes the transition from a pro-inflammatory to an anti-inflammatory phase with the assistance of MuSCs. The resolution of inflammation is required for tissue recovery, in which MuSCs stop proliferation and enter the differentiation process. Therefore, in the early stage of muscle regeneration, IGF2 acts as a 'throttle' of MuSC proliferation response, while in the late stage of muscle regeneration, abundant IGF2 functions as the 'brake' of MuSC proliferation response through inducing resolution of inflammation (Fig. 1). The distinct actions of IGF2 in different phases ensure that those controllable MuSC populations can be fully applied to the subsequent muscle differentiation process, avoiding excessive accumulation of activated MuSCs in local tissue, and improving the application of stem cell during tissue regeneration.

The immunomodulatory ability of MuSCs represents a new mechanism of action by stem cells in the treatment of muscle-related diseases. Immunological and inflammatory processes downstream of dystrophin deficiency contribute to muscle pathology in duchenne muscular dystrophy (DMD). Modulating the inflammatory response and inducing immunological tolerance to de novo dystrophin expression are critical to the success of dystrophin-replacement therapies [90]. The transplantation of MuSCs from healthy donors to DMD patients is based on the assumption that nascent muscle will be formed from the transplanted stem cells. Our findings suggest that MuSCs may also function in taming inflammation in damaged muscle. MuSC-mediated immunomodulation could be of continued importance in completing normal differentiation program and achieving successful dystrophin-replacement therapy. In addition, the immunomodulatory ability of MuSCs provides new potential venues in the treatment of inflammatory diseases by MuSCs. MuSC secretome as a new therapeutic agent can greatly reduce allograft rejection reaction of treated patients, while reducing safety and ethical risks, and facilitate therapeutic effects of stem cells in various inflammatory diseases.

\section{A novel therapeutic use in the COVID-19 pandemic}

The pandemic of coronavirus disease 2019 (COVID-19), caused by severe acute respiratory syndrome coronavirus 2 (SARS-CoV-2), has caused over 4 million deaths up to the present. SARS-CoV-2 infection results in a broad spectrum of clinical manifestations, including both reproductive and neurological implications [91-94]. Indeed, COVID-19 is characterized by excessive production of pro-inflammatory cytokines and acute lung damage associated with patient mortality [95-100]. Various clinical trials based on the potent immunoregulatory ability of MSCs were launched in different countries in various cases with COVID-19 infection. MSC administration appeared to be efficacious in ameliorating overactivated inflammation, contributing to recovery from lung damage, preventing long-term pulmonary disability, and reducing mortality. In addition, MSC infusion in COVID-19 patients had excellent safety [101-108] (Table 1). In this scenario, the therapeutic efficacy of MuSCs equivalent to that of MSCs can be applied in the suppression of hyperactive immune response and promotion of tissue repair, as in DSS-induced IBD.

\section{Perspective}

As mentioned above, MuSCs do not only have wellknown muscle differentiation functions, but also possess important immunomodulatory properties. The relationship between MuSCs and immune cells is bidirectional. In addition to passively receiving inflammatory cues from immune cells for proliferation and differentiation, MuSCs can also actively secrete immunomodulatory factors to induce the resolution of inflammation. Based on the immunoregulatory effect of stem cells, more than 1000 clinical disease treatment studies of MSCs have been carried out around the world. However, there are only dozens of cases of clinical research involving MuSCs, and they are fully focused on the treatment of skeletal muscle diseases based on the muscle differentiation function of MuSCs. The research on the immunoregulatory function of MuSCs will further broaden the application fields of MuSCs. MuSCs are expected to become one of the important stem cell types for the treatment of inflammatory diseases in the foreseeable future.

\section{Authors' contributions}

GM, AV, YW, CS and YS conceived the project; JF and CF wrote the manuscript; WC, PH, ZL, MZ, YH and CX contributed to literature collection and discussion; JF and CF prepared Figs. 1 and 2 through BioRender.com. All authors read and approved the final manuscript. 


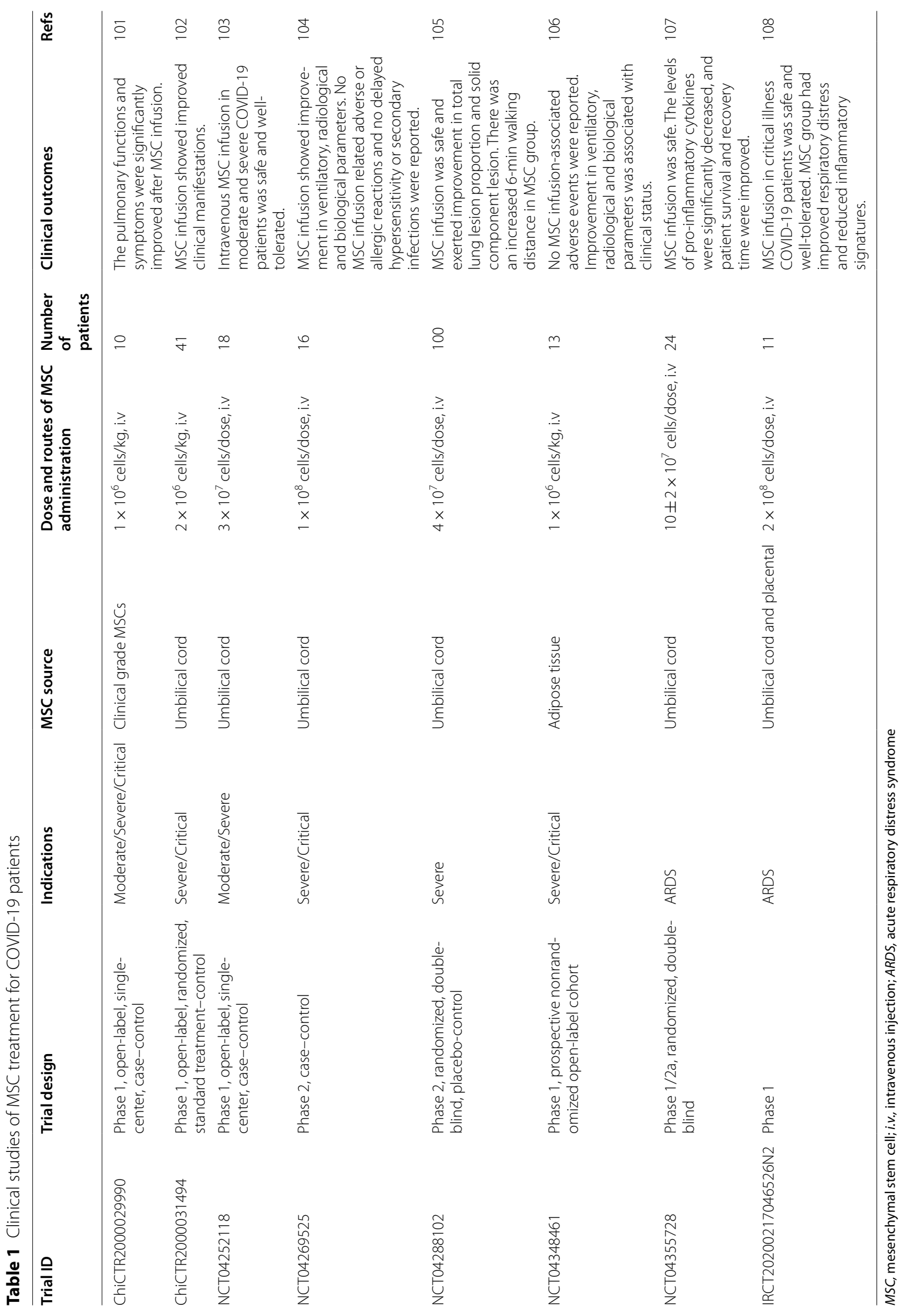




\section{Funding}

This study was supported by funds from the Scientific Innovation Project of the Chinese Academy of Sciences (XDA16020403), the National Key R\&D Program of China (2018YFA0107500), the National Natural Science Foundation of China (81930085, 81672797, 81530043, and 81802864), State Key Laboratory of Radiation Medicine and Protection, Soochow University (GZN1201804 and GZN1201903), National Center for International Research-Cambridge-Su Genomic Research Center (2017B01012), the Natural Science Foundation of the Jiangsu Higher Education Institutions of China (20KJB180005), the Associazione Italiana per la Ricerca contro il Cancro (AIRC) (IG\#20473; 2018-2022), Fondazione Luigi Maria Monti IDI-IRCCS (R.C.), Ministry of Health \& MAECI Italy-China Science and Technology Cooperation (\#PGR00961) and Regione Lazio through Lazio Innova Progetto Gruppo di Ricerca n 85-2017-14986; n 33 \&55-2021-T0002E0001.

\section{Availability of data and materials}

Not applicable.

\section{Declarations}

Ethics approval and consent to participate

Not applicable.

\section{Consent for publication}

Not applicable.

\section{Competing interests}

GM, AV, YW and YS are members of the Editorial board of Biology Direct. The authors declare that they have no financial or ethical competing interests.

\begin{abstract}
Author details
${ }^{1}$ The Third Affiliated Hospital of Soochow University, Institutes for Translational Medicine, State Key Laboratory of Radiation Medicine and Protection, Medical College of Soochow University, 199 Renai Road, Suzhou 215123, Jiangsu, People's Republic of China. ${ }^{2}$ Department of Experimental Medicine and Biochemical Sciences, TOR, University of Rome Tor Vergata, Rome, Italy. ${ }^{3}$ Laboratory Animal Center, Medical College of Soochow University, Suzhou, Jiangsu, People's Republic of China. ${ }^{4}$ Faculty of Biology, Medicine and Health, University of Manchester, Manchester M13 9PT, UK. ${ }^{5}$ Shanghai Institute of Nutrition and Health, Shanghai Institutes for Biological Sciences, Chinese Academy of Sciences, 320 Yueyang Road, Shanghai 200031, People's Republic of China.
\end{abstract}

\section{Received: 18 September 2021 Accepted: 12 October 2021} Published online: 20 October 2021

\section{References}

1. Haas BJ, Whited JL. Advances in decoding axolotl limb regeneration. Trends Genet. 2017;33(8):553-65.

2. Nacu E, Tanaka EM. Limb regeneration: a new development? Annu Rev Cell Dev Biol. 2011;27:409-40.

3. Reddien PW. The cellular and molecular basis for planarian regeneration. Cell. 2018;175(2):327-45.

4. Aboobaker AA. Planarian stem cells: a simple paradigm for regeneration. Trends Cell Biol. 2011;21(5):304-11.

5. Mauretti A, Neri A, Kossover O, Seliktar D, Nardo PD, Melino S. Design of a novel composite $\mathrm{H} 2 \mathrm{~S}$-releasing hydrogel for cardiac tissue repair. Macromol Biosci. 2016;16(6):847-58.

6. Lamastra FR, De Angelis R, Antonucci A, Salvatori D, Prosposito P, Casalboni M, Congestri R, Melino S, Nanni F. Polymer composite random lasers based on diatom frustules as scatterers. Rsc Adv. 2014;4(106):61809-16.

7. Ciocci M, Mochi F, Carotenuto F, Di Giovanni E, Prosposito P, Francini R, De Matteis F, Reshetov I, Casalboni M, Melino S, et al. Scaffold-inscaffold potential to induce growth and differentiation of cardiac progenitor cells. Stem Cells Dev. 2017;26(19):1438-47.

8. Aurora AB, Olson EN. Immune modulation of stem cells and regeneration. Cell Stem Cell. 2014;15(1):14-25.
9. Metchnikoff E. Lectures on the comparative pathology of inflammation; delivered at the Pasteur Institute in 1891. New York: Dover; 1968.

10. Pallucca R, Visconti S, Camoni L, Cesareni G, Melino S, Panni S, Torreri P, Aducci P. Specificity of epsilon and non-epsilon isoforms of arabidopsis 14-3-3 proteins towards the H+-ATPase and other targets. PLoS OsNE. 2014;9(6):e90764.

11. Lin C, Li H, Liu J, Hu Q, Zhang S, Zhang N, Liu L, Dai Y, Cao D, Li X, et al. Arginine hypomethylation-mediated proteasomal degradation of histone $\mathrm{H} 4$-an early biomarker of cellular senescence. Cell Death Differ. 2020;27(9):2697-709.

12. Melino S, Nepravishta R, Bellomaria A, Di Marco S, Paci M. Nucleic acid binding of the RTN1-C C-terminal region: toward the functional role of a reticulon protein. Biochemistry. 2009;48(2):242-53.

13. Liu Z, Zhang H, Hu Y, Liu D, Li L, Li C, Wang Q, Huo J, Liu H, Xie N, et al. Critical role of histone $\mathrm{H} 3$ lysine 27 demethylase $\mathrm{Kdm} 6 \mathrm{~b}$ in the homeostasis and function of medullary thymic epithelial cells. Cell Death Differ. 2020;27(10):2843-55.

14. Lee H, Hong Y, Kong G, Lee DH, Kim M, Tran Q, Cho H, Kim C, Park S, $\mathrm{Kim} \mathrm{SH}$, et al. Yin Yang 1 is required for PHD finger protein 20-mediated myogenic differentiation in vitro and in vivo. Cell Death Differ. 2020;27(12):3321-36.

15. Bellomaria A, Barbato G, Melino G, Paci M, Melino S. Recognition of p63 by the E3 ligase ITCH: effect of an ectodermal dysplasia mutant. Cell Cycle. 2010;9(18):3730-9.

16. Perna S, Pinoli P, Ceri S, Wong L. NAUTICA: classifying transcription factor interactions by positional and protein-protein interaction information. Biol Direct. 2020;15(1):13.

17. Mainieri A, Haig D. Retrotransposon gag-like 1 (RTL1) and the molecular evolution of self-targeting imprinted microRNAs. Biol Direct. 2019;14(1):18.

18. Patthy $L$. Exon skipping-rich transcriptomes of animals reflect the significance of exon-shuffling in metazoan proteome evolution. Biol Direct. 2019;14(1):2.

19. Zhang N, Zhang Y, Qian H, Wu S, Cao L, Sun Y. Selective targeting of ubiquitination and degradation of PARP1 by E3 ubiquitin ligase WWP2 regulates isoproterenol-induced cardiac remodeling. Cell Death Differ. 2020;27(9):2605-19.

20. Damgaard RB, Jolin HE, Allison MED, Davies SE, Titheradge HL, McKenzie ANJ, Komander D. OTULIN protects the liver against cell death, inflammation, fibrosis, and cancer. Cell Death Differ. 2020;27(5):1457-74.

21. Roberts JZ, Holohan C, Sessler T, Fox J, Crawford N, Riley JS, Khawaja H, Majkut J, Evergren E, Humphreys LM, et al. The SCF(Skp2) ubiquitin ligase complex modulates TRAIL-R2-induced apoptosis by regulating FLIP(L). Cell Death Differ. 2020;27(9):2726-41.

22. $Y u$ H, Ding J, Zhu H, Jing $Y$, Zhou $H$, Tian H, Tang $K$, Wang G, Wang $X$. LOXL1 confers antiapoptosis and promotes gliomagenesis through stabilizing BAG2. Cell Death Differ. 2020;27(11):3021-36.

23. Sladky VC, Villunger A. Uncovering the PIDDosome and caspase-2 as regulators of organogenesis and cellular differentiation. Cell Death Differ. 2020;27(7):2037-47.

24. Klionsky DJ. Autophagy participates in, well, just about everything. Cell Death Differ. 2020;27(3):831-2.

25. Yang Y, Klionsky DJ. Autophagy and disease: unanswered questions. Cell Death Differ. 2020;27(3):858-71.

26. Vance JE. Inter-organelle membrane contact sites: implications for lipid metabolism. Biol Direct. 2020;15(1):24.

27. Duggal NA, Niemiro G, Harridge SDR, Simpson RJ, Lord JM. Can physical activity ameliorate immunosenescence and thereby reduce age-related multi-morbidity? Nat Rev Immunol. 2019;19(9):563-72.

28. Tidball JG. Regulation of muscle growth and regeneration by the immune system. Nat Rev Immunol. 2017;17(3):165-78.

29. Yang W, Hu P. Hierarchical signaling transduction of the immune and muscle cell crosstalk in muscle regeneration. Cell Immunol. 2018;326:2-7.

30. Farup J, Madaro L, Puri PL, Mikkelsen UR. Interactions between muscle stem cells, mesenchymal-derived cells and immune cells in muscle homeostasis, regeneration and disease. Cell Death Dis. 2015;6:e1830. 
31. Almada AE, Wagers AJ. Molecular circuitry of stem cell fate in skeletal muscle regeneration, ageing and disease. Nat Rev Mol Cell Biol. 2016;17(5):267-79.

32. Chazaud B. Inflammation and skeletal muscle regeneration: leave it to the macrophages! Trends Immunol. 2020;41(6):481-92.

33. Sass FA, Fuchs M, Pumberger M, Geissler S, Duda GN, Perka C, SchmidtBleek K. Immunology guides skeletal muscle regeneration. Int J Mol Sci. 2018;19(3):66

34. Frenette J, Cai B, Tidball JG. Complement activation promotes muscle inflammation during modified muscle use. Am J Pathol. 2000;156(6):2103-10.

35. Collins RA, Grounds MD. The role of tumor necrosis factor-alpha (TNFalpha) in skeletal muscle regeneration. studies in TNF-alpha(-/-) and TNF-alpha(-/-)/LT-alpha(-/-) mice. J Histochem Cytochem. 2001;49(8):989-1001.

36. Radley HG, Grounds MD. Cromolyn administration (to block mast cell degranulation) reduces necrosis of dystrophic muscle in $\mathrm{mdx}$ mice. Neurobiol Dis. 2006;23(2):387-97.

37. Sugimoto MA, Vago JP, Perretti M, Teixeira MM. Mediators of the resolution of the inflammatory response. Trends Immunol. 2019;40(3):212-27.

38. Tidball JG, Villalta SA. Regulatory interactions between muscle and the immune system during muscle regeneration. Am J Physiol Regul Integr Comp Physiol. 2010;298(5):R1173-1187.

39. Yang W, Hu P. Skeletal muscle regeneration is modulated by inflammation. J Orthop Translat. 2018;13:25-32.

40. Sciorati C, Rigamonti E, Manfredi AA, Rovere-Querini P. Cell death, clearance and immunity in the skeletal muscle. Cell Death Differ. 2016;23(6):927-37.

41. Heredia JE, Mukundan L, Chen FM, Mueller AA, Deo RC, Locksley RM, Rando TA, Chawla A. Type 2 innate signals stimulate fibro/adipogenic progenitors to facilitate muscle regeneration. Cell. 2013;153(2):376-88.

42. Martinez CO, McHale MJ, Wells JT, Ochoa O, Michalek JE, McManus LM, Shireman PK. Regulation of skeletal muscle regeneration by CCR2activating chemokines is directly related to macrophage recruitment. Am J Physiol Regul Integr Comp Physiol. 2010;299(3):R832-842.

43. Contreras-Shannon V, Ochoa O, Reyes-Reyna SM, Sun D, Michalek JE, Kuziel WA, McManus LM, Shireman PK. Fat accumulation with altered inflammation and regeneration in skeletal muscle of CCR2-/- mice following ischemic injury. Am J Physiol Cell Physiol. 2007;292(2):C953-967.

44. Shireman PK, Contreras-Shannon V, Ochoa O, Karia BP, Michalek JE, McManus LM. MCP-1 deficiency causes altered inflammation with impaired skeletal muscle regeneration. J Leukoc Biol. 2007;81(3):775-85.

45. Warren GL, Hulderman T, Mishra D, Gao X, Millecchia L, O'Farrell L, Kuziel WA, Simeonova PP. Chemokine receptor CCR2 involvement in skeletal muscle regeneration. FASEB J. 2005;19(3):413-5.

46. Arnold L, Henry A, Poron F, Baba-Amer Y, van Rooijen N, Plonquet A, Gherardi RK, Chazaud B. Inflammatory monocytes recruited after skeletal muscle injury switch into antiinflammatory macrophages to support myogenesis. J Exp Med. 2007;204(5):1057-69.

47. Zhang C, Wang C, Li Y, Miwa T, Liu C, Cui W, Song WC, Du J. Complement C3a signaling facilitates skeletal muscle regeneration by regulating monocyte function and trafficking. Nat Commun. 2017:8(1):2078.

48. Patsalos A, Tzerpos P, Wei X, Nagy L. Myeloid cell diversification during regenerative inflammation: Lessons from skeletal muscle. Semin Cell Dev Biol. 2021;6:66.

49. Martinez FO, Gordon S. The M1 and M2 paradigm of macrophage activation: time for reassessment. F1000Prime Rep. 2014;6:13.

50. Saclier M, Yacoub-Youssef H, Mackey AL, Arnold L, Ardjoune H, Magnan M, Sailhan F, Chelly J, Pavlath GK, Mounier R, et al. Differentially activated macrophages orchestrate myogenic precursor cell fate during human skeletal muscle regeneration. Stem Cells. 2013;31(2):384-96.

51. Panduro M, Benoist C, Mathis D. Treg cells limit IFN-gamma production to control macrophage accrual and phenotype during skeletal muscle regeneration. Proc Natl Acad Sci USA. 2018;115(11):E2585-93.

52. Cheng M, Nguyen MH, Fantuzzi G, Koh TJ. Endogenous interferongamma is required for efficient skeletal muscle regeneration. Am J Physiol Cell Physiol. 2008;294(5):C1183-1191.

53. Wang X, Wu H, Zhang Z, Liu S, Yang J, Chen X, Fan M, Wang X. Effects of interleukin-6, leukemia inhibitory factor, and ciliary neurotrophic factor on the proliferation and differentiation of adult human myoblasts. Cell Mol Neurobiol. 2008;28(1):113-24.

54. Broussard SR, McCusker RH, Novakofski JE, Strle K, Shen WH, Johnson RW, Dantzer R, Kelley KW. IL-1beta impairs insulin-like growth factor i-induced differentiation and downstream activation signals of the insulin-like growth factor i receptor in myoblasts. J Immunol. 2004;172(12):7713-20.

55. Langen RC, Van Der Velden JL, Schols AM, Kelders MC, Wouters EF, Janssen-Heininger YM. Tumor necrosis factor-alpha inhibits myogenic differentiation through MyoD protein destabilization. FASEB J. 2004;18(2):227-37.

56. Saclier M, Cuvellier S, Magnan M, Mounier R, Chazaud B. Monocyte/ macrophage interactions with myogenic precursor cells during skeletal muscle regeneration. FEBS J. 2013;280(17):4118-30.

57. Lemos DR, Babaeijandaghi F, Low M, Chang CK, Lee ST, Fiore D, Zhang $\mathrm{RH}$, Natarajan A, Nedospasov SA, Rossi FM. Nilotinib reduces muscle fibrosis in chronic muscle injury by promoting TNF-mediated apoptosis of fibro/adipogenic progenitors. Nat Med. 2015;21(7):786-94.

58. Ratnayake D, Nguyen PD, Rossello FJ, Wimmer VC, Tan JL, Galvis LA, Julier Z, Wood AJ, Boudier T, Isiaku Al, et al. Macrophages provide a transient muscle stem cell niche via NAMPT secretion. Nature. 2021;591(7849):281-7.

59. Fu X, Xiao J, Wei Y, Li S, Liu Y, Yin J, Sun K, Sun H, Wang H, Zhang Z, et al. Combination of inflammation-related cytokines promotes long-term muscle stem cell expansion. Cell Res. 2015;25(6):655-73.

60. Quarta M, Rando TA. Mimicking the niche: cytokines expand muscle stem cells. Cell Res. 2015;25(7):761-2.

61. Varga T, Mounier R, Patsalos A, Gogolak P, Peloquin M, Horvath A, Pap A, Daniel B, Nagy G, Pintye E, et al. Macrophage PPARgamma, a lipid activated transcription factor controls the growth factor GDF3 and skeletal muscle regeneration. Immunity. 2016:45(5):1038-51.

62. Latroche C, Weiss-Gayet M, Muller L, Gitiaux C, Leblanc P, Liot S, BenLarbi S, Abou-Khalil R, Verger N, Bardot P, et al. Coupling between myogenesis and angiogenesis during skeletal muscle regeneration is stimulated by restorative macrophages. Stem Cell Rep. 2017;9(6):2018-33.

63. Diskin C, Ryan TAJ, O'Neill LAJ. Modification of proteins by metabolites in immunity. Immunity. 2021;54(1):19-31.

64. Muri J, Kopf M. Redox regulation of immunometabolism. Nat Rev Immunol. 2021;21(6):363-81.

65. Giannakis N, Sansbury BE, Patsalos A, Hays TT, Riley CO, Han X, Spite M, Nagy L. Dynamic changes to lipid mediators support transitions among macrophage subtypes during muscle regeneration. Nat Immunol. 2019;20(5):626-36.

66. Mounier R, Theret M, Arnold L, Cuvellier S, Bultot L, Goransson O, Sanz N, Ferry A, Sakamoto K, Foretz M, et al. AMPKalpha1 regulates macrophage skewing at the time of resolution of inflammation during skeletal muscle regeneration. Cell Metab. 2013;18(2):251-64.

67. Tonkin J, Temmerman L, Sampson RD, Gallego-Colon E, Barberi L, Bilbao D, Schneider MD, Musaro A, Rosenthal N. Monocyte/macrophagederived IGF-1 orchestrates murine skeletal muscle regeneration and modulates autocrine polarization. Mol Ther. 2015;23(7):1189-200.

68. Tidball JG, Welc SS. Macrophage-derived IGF-1 is a potent coordinator of myogenesis and inflammation in regenerating muscle. Mol Ther. 2015;23(7):1134-5.

69. Wei J, Gronert K. Eicosanoid and specialized proresolving mediator regulation of lymphoid cells. Trends Biochem Sci. 2019;44(3):214-25.

70. Peebles RS Jr. Prostaglandins in asthma and allergic diseases. Pharmacol Ther. 2019:193:1-19.

71. Norel $X$, Sugimoto $Y$, Ozen $G$, Abdelazeem $H$, Amgoud $Y$, Bouhadoun A, Bassiouni W, Goepp M, Mani S, Manikpurage HD, et al. International union of basic and clinical pharmacology. CIX. Differences and similarities between human and rodent prostaglandin E2 receptors (EP1-4) and prostacyclin receptor (IP): specific roles in pathophysiologic conditions. Pharmacol Rev. 2020;72(4):910-68.

72. Ho ATV, Palla AR, Blake MR, Yucel ND, Wang YX, Magnusson KEG, Holbrook CA, Kraft PE, Delp SL, Blau HM. Prostaglandin E2 is essential for efficacious skeletal muscle stem-cell function, augmenting regeneration and strength. Proc Natl Acad Sci USA. 2017;114(26):6675-84.

73. Panduro M, Benoist C, Mathis D. Tissue tregs. Annu Rev Immunol. 2016:34:609-33. 
74. Kuswanto W, Burzyn D, Panduro M, Wang KK, Jang YC, Wagers AJ, Benoist C, Mathis D. Poor repair of skeletal muscle in aging mice reflects a defect in local, interleukin-33-dependent accumulation of regulatory T cells. Immunity. 2016;44(2):355-67.

75. Burzyn D, Kuswanto W, Kolodin D, Shadrach JL, Cerletti M, Jang Y, Sefik E, Tan TG, Wagers AJ, Benoist C, et al. A special population of regulatory T cells potentiates muscle repair. Cell. 2013;155(6):1282-95.

76. Villalta SA, Rosenthal W, Martinez L, Kaur A, Sparwasser T, Tidball JG, Margeta M, Spencer MJ, Bluestone JA. Regulatory T cells suppress muscle inflammation and injury in muscular dystrophy. Sci Transl Med. 2014;6(258):258ra142.

77. Afzali AM, Muntefering T, Wiendl H, Meuth SG, Ruck T. Skeletal muscle cells actively shape (auto)immune responses. Autoimmun Rev. 2018;17(5):518-29.

78. Zhou S, Zhang W, Cai G, Ding Y, Wei C, Li S, Yang Y, Qin J, Liu D, Zhang $\mathrm{H}$, et al. Myofiber necroptosis promotes muscle stem cell proliferation via releasing Tenascin- $C$ during regeneration. Cell Res. 2020;30(12):1063-77.

79. Fang J, Zhang S, Liu Z, Pan Y, Cao L, Hou P, Chen Y, Zhang Y, Li X, Liu R, et al. Skeletal muscle stem cells confer maturing macrophages antiinflammatory properties through insulin-like growth factor-2. Stem Cells Transl Med. 2020;9(7):773-85.

80. Mittal M, Tiruppathi C, Nepal S, Zhao YY, Grzych D, Soni D, Prockop DJ, Malik AB. TNFalpha-stimulated gene-6 (TSG6) activates macrophage phenotype transition to prevent inflammatory lung injury. Proc Natl Acad Sci USA. 2016;113(50):E8151-8.

81. Sala E, Genua M, Petti L, Anselmo A, Arena V, Cibella J, Zanotti L, D'Alessio S, Scaldaferri F, Luca G, et al. Mesenchymal stem cells reduce colitis in mice via release of TSG6, independently of their localization to the intestine. Gastroenterology. 2015;149(1):163e120-176e120.

82. Zhang S, Fang J, Liu Z, Hou P, Cao L, Zhang Y, Liu R, Li Y, Shang Q, Chen $Y$, et al. Inflammatory cytokines-stimulated human muscle stem cells ameliorate ulcerative colitis via the IDO-TSG6 axis. Stem Cell Res Ther. 2021;12(1):50

83. Peruzzotti-Jametti L, Bernstock JD, Vicario N, Costa ASH, Kwok CK, Leonardi T, Booty LM, Bicci I, Balzarotti B, Volpe G, et al. Macrophage-derived extracellular succinate licenses neural stem cells to suppress chronic neuroinflammation. Cell Stem Cell. 2018;22(3):355e313-368e313.

84. Wang Y, Chen X, Cao W, Shi Y. Plasticity of mesenchymal stem cells in immunomodulation: pathological and therapeutic implications. Nat Immunol. 2014;15(11):1009-16.

85. Shi Y, Wang Y, Li Q, Liu K, Hou J, Shao C, Wang Y. Immunoregulatory mechanisms of mesenchymal stem and stromal cells in inflammatory diseases. Nat Rev Nephrol. 2018;14(8):493-507.

86. Fry CS, Kirby TJ, Kosmac K, McCarthy JJ, Peterson CA. Myogenic progenitor cells control extracellular matrix production by fibroblasts during skeletal muscle hypertrophy. Cell Stem Cell. 2017;20(1):56-69.

87. Charville GW, Cheung TH, Yoo B, Santos PJ, Lee GK, Shrager JB, Rando TA. Ex vivo expansion and in vivo self-renewal of human muscle stem cells. Stem Cell Rep. 2015;5(4):621-32.

88. Du L, Lin L, Li Q, Liu K, Huang Y, Wang X, Cao K, Chen X, Cao W, Li F, et al. IGF-2 preprograms maturing macrophages to acquire oxidative phosphorylation-dependent anti-inflammatory properties. Cell Metab. 2019;29(6):1363e1368-1375e1368.

89. Wang $X$, Lin L, Lan B, Wang Y, Du L, Chen X, Li Q, Liu K, Hu M, Xue Y, et al. IGF2R-initiated proton rechanneling dictates an anti-inflammatory property in macrophages. Sci Adv. 2020;6(48):66.

90. Rosenberg AS, Puig M, Nagaraju K, Hoffman EP, Villalta SA, Rao VA, Wakefield LM, Woodcock J. Immune-mediated pathology in Duchenne muscular dystrophy. Sci Transl Med. 2015;7(299rv294).

91. Matsuyama T, Kubli SP, Yoshinaga SK, Pfeffer K, MakTW. An aberrant STAT pathway is central to COVID-19. Cell Death Differ. 2020;27(12):3209-25.

92. Celardo I, Pace L, Cifaldi L, Gaudio C, Barnaba V. The immune system view of the coronavirus SARS-CoV-2. Biol Direct. 2020;15(1):30.

93. Verkhratsky A, Li Q, Melino S, Melino G, Shi Y. Can COVID-19 pandemic boost the epidemic of neurodegenerative diseases? Biol Direct. 2020;15(1):28
94. Chen J, Lu H, Melino G, Boccia S, Piacentini M, Ricciardi W, Wang Y, Shi Y, Zhu T. COVID-19 infection: the China and Italy perspectives. Cell Death Dis. 2020;11(6):438.

95. Agrati C, Sacchi A, Bordoni V, Cimini E, Notari S, Grassi G, Casetti R, Tartaglia E, Lalle E, D'Abramo A, et al. Expansion of myeloid-derived suppressor cells in patients with severe coronavirus disease (COVID-19). Cell Death Differ. 2020;27(11):3196-207.

96. Noce A, Santoro ML, Marrone G, D'Agostini C, Amelio I, Duggento A, Tesauro M, Di Daniele N. Serological determinants of COVID-19. Biol Direct. 2020;15(1):21.

97. Ehsani S. COVID-19 and iron dysregulation: distant sequence similarity between hepcidin and the novel coronavirus spike glycoprotein. Biol Direct. 2020;15(1):19.

98. Shi Y, Wang Y, Shao C, Huang J, Gan J, Huang X, Bucci E, Piacentini M, Ippolito G, Melino G. COVID-19 infection: the perspectives on immune responses. Cell Death Differ. 2020;27(5):1451-4.

99. Sharma A, Kumar Sharma S, Shi Y, Bucci E, Carafoli E, Melino G, Bhattacherjee A, Das G. BCG vaccination policy and preventive chloroquine usage: Do they have an impact on COVID-19 pandemic? Cell Death Dis. 2020;11(7):516.

100. Karki R, Sharma BR, Tuladhar S, Williams EP, Zalduondo L, Samir P, Zheng M, Sundaram B, Banoth B, Malireddi RKS, et al. Synergism of TNF-alpha and IFN-gamma triggers inflammatory cell death, tissue damage, and mortality in SARS-CoV-2 infection and cytokine shock syndromes. Cell. 2021;184(1):149e117-168e117.

101. Leng Z, Zhu R, Hou W, Feng Y, Yang Y, Han Q, Shan G, Meng F, Du D, Wang $S$, et al. Transplantation of ACE2(-) mesenchymal stem cells improves the outcome of patients with COVID-19 pneumonia. Aging Dis. 2020;11(2):216-28.

102. Shu L, Niu C, Li R, Huang T, Wang Y, Huang M, Ji N, Zheng Y, Chen X, Shi L, et al. Treatment of severe COVID-19 with human umbilical cord mesenchymal stem cells. Stem Cell Res Ther. 2020;1 1(1):361.

103. Meng F, Xu R, Wang $S$, Xu Z, Zhang C, Li Y, Yang T, Shi L, Fu J, Jiang T, et al. Human umbilical cord-derived mesenchymal stem cell therapy in patients with COVID-19: a phase 1 clinical trial. Signal Transduct Target Ther. 2020:5(1):172.

104. Feng Y, Huang J, Wu J, Xu Y, Chen B, Jiang L, Xiang H, Peng Z, Wang $X$. Safety and feasibility of umbilical cord mesenchymal stem cells in patients with COVID-19 pneumonia: a pilot study. Cell Prolif. 2020:53(12):12947.

105. Shi L, Huang H, Lu X, Yan X, Jiang X, Xu R, Wang S, Zhang C, Yuan X, Xu $Z$, et al. Effect of human umbilical cord-derived mesenchymal stem cells on lung damage in severe COVID-19 patients: a randomized, double-blind, placebo-controlled phase 2 trial. Signal Transduct Target Ther. 2021;6(1):58.

106. Sanchez-Guijo F, Garcia-Arranz M, Lopez-Parra M, Monedero P, Mata-Martinez C, Santos A, Sagredo V, Alvarez-Avello JM, Guerrero JE, Perez-Calvo C, et al. Adipose-derived mesenchymal stromal cells for the treatment of patients with severe SARS-CoV-2 pneumonia requiring mechanical ventilation. A proof of concept study. EClinicalMedicine. 2020:25:100454.

107. Lanzoni G, Linetsky E, Correa D, Messinger Cayetano S, Alvarez RA, Kouroupis D, Alvarez Gil A, Poggioli R, Ruiz P, Marttos AC, et al. Umbilical cord mesenchymal stem cells for COVID-19 acute respiratory distress syndrome: a double-blind, phase 1/2a, randomized controlled trial. Stem Cells Transl Med. 2021;10(5):660-73.

108. Hashemian SR, Aliannejad R, Zarrabi M, Soleimani M, Vosough M, Hosseini SE, Hossieni H, Keshel SH, Naderpour Z, Hajizadeh-Saffar E, et al. Mesenchymal stem cells derived from perinatal tissues for treatment of critically ill COVID-19-induced ARDS patients: a case series. Stem Cell Res Ther. 2021;12(1):91.

\section{Publisher's Note}

Springer Nature remains neutral with regard to jurisdictional claims in published maps and institutional affiliations. 